\title{
ESCREVER, UMA PRÁTICA RADICAL E POSSÍVEL ${ }^{1}$
}

\author{
Paulo Venturelli *
}

Eu jamais poderia sentar à minha mesa com seriedade pare escrever uma linha sequer por qualquer outro motivo que não fosse salvar minha vida. Jane Austen

U ma das comprovações mais cvidentes do fracasso da educação está no bloqueio que a maioria dos alunos tem para escrever. Poucos escrevem e escrevem mal. Poucos escrevem e quando escrevem, seus textos são uma colcha de retalho de frases fcitas, o texto ressoa falso, sem qualquer força de vida. E os alunos, em número expressivo, simplesmente detestam escrever e encaram a prática da escrita como mais um dos tormentos impingidos pela escola. E nossos esforços rendem nada ou quase nada: esbarramos na passividade, na apatia do aluno, fatores que nos levam à irritação e não percebemos que essas atitudes dos alunos estão

* Univ. Federal do Paraná

1 Este ensaio é um resumo da reflexão com que abrimos a oficina de texto para professores da rede pública, em agosto de 1991. Obviamente, aqui estão apenas eshoçadas questões que na oportunidade pudemos aprofundar de modo mais prático, visando à transformação das "aulas de redação" em "oficinas de texto." 
ligadas a um forma de defesa: protegem-se assim da vulnerabilidade e da confusão em que se sentem envolvidos. ${ }^{2}$

Tentando, se possível, isolar o tópico que nos ocupa hoje - a produção de tex to do aluno - talvez possamos ter uma base mais sólida de percepção que pelo menos encaminhe para uma perspectiva de saída ou contorne a aridez burocrática e funcional a que muitas vezes reduzem-se nossas aulas. É nossa certeza que precisamos ter objetivos claros em tudo o que fazemos. Na educação isso é um principio indiscutivel. Verificando o depoimento de escritores, constatamos que definir o ato de escrever e a razão que os leva à prática da escrita não são tarefas fáceis. Porém, quando estamos em sala de aula, ocupados com a obrigaçāo de fazer o aluno escrever, devemos ter alguns pontos bem delineados: afinal, por que, para que um aluno precisa escrever? A partir do instante em que elucidarmos tais tópicos, alguma coisa renderá dividendos positivos a todos. Ao buscarmos a definiçāo do problema, entra em cena nossa visão de mundo e, nele nossa concepçāo de educaçāo, de homem, de aprendizagem, de escritura. Se somos dos que acreditam que escrever é um dom de quem é possuidor de talento superior, de início já partirmos de uma colocação derrotista, de um ângulo classicista que justificaria a divisão entre os que tém o poder de escrever e os que não tēm esse poder. Escrever é uma prática social, fruto da interação com o mundo e ponte de intercessão com este mundo. Se o homem é social, se a consciência é social, escrever nāo é diferente. ${ }^{3}$ Aqui é evidente o primeiro erro da escola: forçamos o aluno a escrever como um ato eminentemente individual e fazemos malabarismos metafísicos para despertar sua criatividade. Com a maior boa vontade, muitas vezes tentamos despertar os subterraneos do aluno, como se lí estivesse intacto o seu maior tesouro que, emergindo, transfonnaria o menino no mago das palavras, rendilhando a sua página com criaçōes originais sopradas pelos deuses. Estamos dizendo que talento para escrever é potencialidade de todos, desde que em sua história aprendam a elaborar esta capacidade de apreensão e entendimento do mundo. $O$ homem se faz escritor, escrevendo, relacionando-se com as linguagens que of fertilizam. Talento é conseqüencia. Os antigos dizjam que escrever é ouvir vozes. Tinham certa razāo. Essas não são vozes mediúnicas, estratosféricas. Quando escrevemos, intervimos nas e com as vozes que

2 CALKINS, Lucy McComick A arte de ensinar a escrever: o desenvolvimento do discurso escrito. Porto Alegre: Anes Médicas, 1989. p. 129.

3 Sobre a questio da formação social da mente, ct. BAKHTIN, Mikhail. Marxismo é filosofia da linguagem. Säo Paulo: Hucitec, 1979: VYGOTSKY. L.S. A formaçäo social ckt mente. São Paulo: Martins Fontes Editora, 1984. 
amoldam nossa constituição de seres vivos na História. Escrever, em vez de magia, é trabalho social e ele se aprende. A natureza humana é também lúdica e no trato com a linguagem podemos assimilar percursos que nos levem a desenvolver uma prática lúdica. Todo este processo tem o nome de autonomia do pensamento, o objetivo que toda educação crítica procura alcançar.

Estas colocações podem parecer abstratas. Tentaremos ao longo da exposição deixá-las mais nitidas. Concretizando o problema: como a escola habitualmente trata a lingua, as linguagens, a escrita? Se olharmos os livros-textos algo salta à vista: estão recheados de produção literária. Pela escola, o aluno parece ser obrigado a aprender que o único discurso existente é o da literatura. E ele, o aluno, encolhido na carteira, sofre o anátema: ou se torna um escritor, papel restrito àquele que tece uma linguagem especialmente poética, ou fica relegado a uma posição de silêncio, na letal sensação de inferioridade e impotência. Aí está uma das razões da vulnerabilidade a que nos referíamos antes. Para não ter diante de si, soando alto, a sensaçāo de inferioridade, esse aluno desliga-se: torna-se apático ou pende para a algazarra, querendo ver tudo pela frente, menos a famigerada aula de redação.

Insistindo na linguagem literária, a escola perde a real dimensão da escrita, porque o aluno tem pouco acesso ao texto informativo e de opinião. Também não o pratica, alienando-se da escrita que perde toda e qualquer função em sua vida. Uma criança $\mathrm{e}$ um adolescente não estão ainda $\mathrm{em}$ condiçōes de exercitar o texto literário. Vivendo, contudo, em contato quase que exclusivo com este, a literatura transforma-se em letra morta, distante, inacessivel, sem qualquer relação de necessidade com a vida destes garotos. Vale dizer: a educação também assassina o leitor. A desvantagem é geral. Com a perda do real significado do texto, o aluno ignora que todo ser humano tem "necessidade de representar sua experiência através da escrita. ${ }^{4}$ Como todos, em qualquer circunstância, gostam de rabiscar por aí, a escola teria de criar com urgência condições para que o aluno, interagindo com o outro, possa adequar-se a uma atividade saudável de escrita, decodificando os discursos existentes e elaborando o seu próprio. Assumindo posição efetiva de uma produção consciente de texto, o aluno passa a ter como organizar o caos que cerca nossa existência c a determina, porque escrever, acima de tudo, é tomar "consciência de que estamos vivos." ${ }^{5}$ E vivos numa relação

4 CALKINS, opt.cit., p.15.

5 LINDBERGH, Anne Morrow. Apud CALKINS, op.cit., p. 15. 
ininterrupta com o outro, sobre quem agimos e que age sobre nós. Não por acaso, John Cheever afirmou que, a partir do instante em que começou a escrever, descobriu "que este era o melhor modo" de colocar sentido em sua vida.

O que fazemos na escola? Abartotamos a turma com uma série de truques mecânicos na vã tentativa de estimulá-la a criar um texto. O máximo que conseguimos é um conglomerado momentāneo de palavras. Passando aquele instante, passado o estado de graça, ninguém escreve mais, porque escrever nāo faz parte de seu projeto de vida. Todos os truques de que lançamos mão têm o mesmo efeito de um choque: despertam uma reação nervosa qualquer e o aluno, como autômato, rabisca um número mais ou menos suficiente de linhas que serāo entregues e corrigidas. Pateticamente tudo se resume a isso. Claro que, nestes termos, escrever é uma tarefa árida e inútil.

Todos temos idéias, sentimentos, lembranças, ódios, sonhos, porque experenciamos o mundo e nele nos constituímos. O aluno deve descobrir que tudo isso vale como matéria de texto. E, ao fazer isso, estará pensando, refletindo, definindo seu local no percurso da História. Todavia, encarar o trabalho de escrever sob esta ótica só será possivel quando escrever tornar-se algo pessoal e interpessoal: ${ }^{6}$ temos de transformar a escrita num projeto de eficácia individual e social. Alcançando-se este projeto, nāo precisaremos mais de nenhuma tramóia para levar o aluno ao texto, nem como produtor, nem como leitor. É para esta direção que se movimenta nossa reflexão: em lugar de aulas de redação, oficincas de texto, para que seja ensinado um novo sentido de escrever como uma função pulsante, genuinamente vital para o aluno, que poderá explorar sua real conexāo com o mundo e, debruçando neste exercício, enriquecer seu processo vivencial com uma imagem mais definida de si mesmo, do universo que habita e, principalmente, das linguagens com as quais ele atua no mundo.

Sabemos de antemão de todas as dificuldades que nós professores tcmos para concretizar estas idéias em sala de aula. Do nosso despreparo profissional as nossas concep̧̧ões muitas vezes nebulosas e mal alinhavadas, dos nossos baixos salários às estruturas autoritárias da escola, das nossas frustrações desgastantes às condiçōes gerais e desfavoráveis do ensino, tudo nos assombra. Mas é só por que a situação é esta que procuramos lutar ainda com energia, pois apenas sob o prisma da luta c do inconformismo nossa função social de educadores pode estar justificada. 
Não é por acaso, não é por nenhuma trama insondável do destino que somos professores. Então, assumir esta tarefa significa ter um olho critico bem afiado sobre nós mesmos, o que implica ter ousadia, correr riscos, experimentar.

O que fazer então? Correndo sempre muito próximo das simplificações, gostariamos de ser didáticos ao convidá-los a pensar mais uma vez sobre o que é realmente escrever, o que é preciso para escrever. De início, algumas condições são apresentadas como essenciais: ${ }^{7}$ a)envolvimento - já que ninguém realiza nada do nada, qualquer autor de texto precisa estar profundamente envolvido com aquilo que irá abordar. Escrever, portanto, é entrar em fusão com um universo amplo de discursos e ao transformá-los, vamos enriquecendo-os com novos acentos, novas colorações; b) escolha da temática (dos tópicos) - pela própria complexidade do mundo no qual estamos inseridos, precisamos selecionar um ângulo com o qual nosso envolvimento, nosso conhecimento são maiores o que facilitará o trânsito, a produção. Ficando em aspectos meramente genéricos, não sairemos daquela colcha de retalhos que já fizemos alusão; c) escolha da forma -envolvidos com um determinado tópico, somos levados a conhecer outras abordagens já realizadas a respeito. Investiremos então na moldagem pessoal que daremos ao nosso texto e é nesta modulação que reside a nem sempre compreendida originalidade; d) escolha da voz (do ponto de vista) mantendo intenso envolvimento com o tema que explanaremos, adotado o caminho pelo qual vamos seguir, é o momento de imprimir nosso ponto de vista. Este, sendo efetivamente novo, provoca o encontro de uma forma nova, porque apenas um pensamento de ruptura é capaz de trazer originalidade ao mundo; e) escolha da audiência - como o texto é uma forma de dialogar com alguém à distância, ${ }^{8}$ precisamos ter consciência eficiente a respeito do interlocutor, escolhendo a melhor linguagem para chegar até ele com total clareza.

Todos estes quesitos conduzem o processo de produção de tex to para a posse e a responsabilidade sobre o que se escreve, ${ }^{9}$ tudo isso materializa o escrever como o projeto pessoal e social de que falávamos acima. Não podemos nunca esquecer que escrever é destilar o mundo, é refratar as linguagens do mundo. Escrevemos porque lemos, vemos, ouvimos, conversamos, vivemos, enfim. Com as posições delineadas antes, podemos des-

Cf.CALKINS, op.cit., p.15-21.

8 MANDRIK, David; FARACO, Carlos Alberto. Prática de redação para estudantes universitários. Petrópolis: Vozes, 1987. p.10.

9 CALKINS, op.cit., p. 19. 
mistificar o fetiche da escrita: escrever não é tarefa de semideuses, mas uma ação possivel, desde que se criem condiçōes para o seu aprendizado. Desmistificar a escrita não significa banalizar a literatura, acreditando que todos serão poetas, romancistas, contistas, etc. Isso é uma outra questão e foge do que estamos discutindo. Desmistificar o texto tem a conotação de colocar na escola a linguagem adequada com a qual o aluno trabalhará em sua produção intelectual. Quando estamos ensinando a escrever, o aluno precisa adotar a certeza de que os discursos impressos são acessíveis e gratificantes, adotar a certeza de que ele, aluno, é também produtor, na medida em que é humano (homo faber) e, sabendo-se produtor, poderá ler melhor toda sorte de texto, irá compartilhar com mais eficácia suas idéias com os outros, terá condiçōes mais expressivas de perceber as idéias dos outros refletindo-se nele e, de um modo mais livre e real, terá também, por esta via, como compartilhar melhor das culturas escritas que tradicionalmente a escola encerra num museu de monstrengos intratáveis. Lendo melhor, ele aguçará sua perspicácia e poderá servir-se das técnicas de seus autores prediletos. Nosso aluno não precisará ser um escritor no sentido restrito do termo, porém, nada impede que ele lance mão do processo de criação de criaçăo literária, do método literário, para tecer um texto opinativo, informativo, ou qualquer outra ordem de necessidade. E, para anto, a oficina de texto precisa conduzir seu trabalho para a criação de um ambiente que estimule o contato do aluno com a escrita e com o mundo. Ninguém nasce homem, a gente torna-se homem, ninguém nasce escritor predestinado, a gente aprende a formar-se como escritor. E, portanto, enquanto a velha pedagogia punha ênfase no resultado, valorizando o texto que era avaliado e premiado ou não com uma nota, depois de passar pelo humilhante sarampāo vermelho do professor, temos de mudar a perspectiva, valorizando o caminho de criação do tex to que não poderá mais ser feito de hoje para hoje ou para amanhã.

Um processo concreto de elaboraçāo textual, nestas condições de oficina, tem fases que, a grosso modo, podemos chamar de ensaio, esboço, revisāo e versão final. ${ }^{10}$ Como produzir um texto num certo sentido é uma investigação, compreendendo o encaminhamento desta elaboração, podemos efetivamente colaborar com o aluno no sentido de que ele invente, 
utilize, adapte as múltiplas estratégias usadas pelas pessoas mais diversas, quando são movidas pela necessidade de escrever. ${ }^{11}$ Desta forma, os estágios podem ser circunscritos da seguinte maneira: a) ensaio - quando alguém está envolvido de verdade e integralmente com alguma coisa, o ensaio passa a ser um modo de vida. No caso que nos ocupa, o aluno precisa ter embutido em si o senso de ser alguém que escreve. Com isso, ele será movido por uma consciência extra que alimentará sempre o seu envolvimento, abrindo os mananciais que ele verterá nos textos. O ensaio é um modo de potencializar a escrita, armazenando as sementes, o que inclui conversas, leitura, filmes, esporte, namoro, festas, etc., em cada ação pinçando alguns elementos para o seu estoque. Na verdade, é aqui que se materializa o escrever como um projeto de vida e não apenas como uma esporádica tarefa escolar. Observando as coisas do mundo, envolvido com elas, o aluno também aprimora seu senso de audiência: como as pessoas reagiriam se eu escrevesse sobre isso? Deste modo, ele mapeia as linhas de um trabalho constante; b) esboço - é uma tarefa que pode ter origem numa imagem visual das tantas em seu acervo, numa idéia mais delineada, num ângulo selecionado entre os milhares que o mundo oferece a toda hora. Esboço são os primeiros esforços práticos, quando aos poucos vamos encontrando o contorno do tema: traçando linhas, jogando palavras, criando blocos verbais que necessariamente ainda não têm muita concatenação entre si. Aqui, nada é definitivo, já que estamos desenvolvendo unidades menores, sem um compromisso maior com o corpo total do texto ainda ignorado. Estamos manipulando e saboreando idéias germinais, brincando com elas, experimentando direções que podem ou não ser confirmadas. Talvez o resultado neste instante seja muito ruim, bronco, muito desconexo, mas precisamos saber que, sem estas engatinhadas inseguras, não daremos os passos efetivos mais tarde; c) revisäo - é o momento de rever o que está construído, ainda que informe e vazio. Como muito acertadamente define Lucy Calkins, o que está escrito torna-se uma lente que nos ajuda a ver/entender o que emerge. Fica, assim, mais fácil seguir uma direção. Da nebulosa inicial, divisamos um contorno mais nítido. Seguindo por ele, acabamos por saber o que efetivamente queremos dizer. Devemos começar de novo, tentando outras modalidades, investigando novas direçōes. $O$ tema, aos

11 Ainda que o objetivo da escola não seja produção litcrária, sugerimos o "método literário" como via possivel. Assim, livros como Os escritores: as históricas entrevistas da Paris Reviw. São Paulo: Cia das Letras, 1988, v.l e 1989, v.2, são preciosos documentos que registram este "método" seguido de diferentes formas pelos escritores. 
poucos, desdobra-se com maior visibilidade e temos em mãos o que pretendemos dizer. Na verdade, é aqui que estamos interagindo com nosso próprio texto, ele tem algo a dizer e ajuda-nos a dar maior clareza ao que vínhamos esgaravatando. O autor torna-se leitor, depois, uma vez mais, autor. Elimino o que está excessivo, insiro outras linhas, altero detalhes, modifico um tipo de texto por outro; d) versão final -chegou a hora das decisōes mais minuciosas. $O$ que ainda está flácido é melhor alinhavado, ganha outra coloração. Estamos a trabalhar com a própria emoção que brota do texto em construçāo: ele vai of erecendo suas carnes ao nosso trabalho e mergulhamos nele percebendo suas variadas possibilidades de enriquecimento. A forma do texto desvenda-se e nós a moldamos melhor. Ouvimos seus sons, experimentamos seus sabores. A colagem daqui-com-ali traz iluminaçōes mais carregadas de sentidos. Novos desafios vêm à tona com a personalidade que o texto já evidencia. Enxugamos, ligamos, religamos, tornamos cada ponto um pouco mais claro. Enfim, eis o texto, pronto para novos retoques. Afastamo-nos da página (por isso, a questão do tempo é importantíssima; um texto nunca pode ser feito a toque-de-caixa.) e, outra vez na pele do leitor, lemos objetiva e criticamente tudo o que está no papel, para tudo e tudo recomeçar uma vez mais.

Como é justo supor, nada disso ocorre de forma estanque e assepticamente dividida em clichês laboratoriais, nem tem o rigor de uma prancheta milimetricamente calculada, porque o fluxo deve ser mantido segundo o ritmo de cada um.

Estas colocações, aqui parciais pelo pouco espaço que temos para desenvolver a complexidade do que venha a ser uma oficina, ajudam-nos a entender que é essencial uma mudança de filosofia e de atitude. Passar um tema e mandar o aluno escrever, ler um texto e pedir a reescritura, tocar uma música, sugerindo que o aluno dè suas impressōes, são artimanhas fora de cogitação se concentradas apenas nelas mesmas. Nosso esforço deve ser guiado no sentido de criar uma interação profunda entre o aluno, suas cercanias e seu texto em desenvolvimento e tudo exigirá de todos nós um empenho redobrado e prolongado, exigirá muita persistência e a bíblica paciência de Jó, porque a primeira acusação que será levantada contra nós é que nossas aulas são uma bagunça, que alvoraçamos os alunos, que matamos o tempo. E, acima de tudo, não devemos esquecer um detalhe importante: vivemos numa sociedade utilitarista, imediatista, superficial, onde tudo precisa ser instantaneo e facilitado ${ }^{12}$ e o que está sendo proposto 
ć uma absorção total num projeto de trabalho que não dará fruto logo amanhã.

Uma oficina nestas condições precisará de um funcionamento cotidiano, o que certamente é mais fácil para os professores de $1^{\mathrm{a}}$ a $4^{\mathrm{a}}$, que têm uma convivência maior com os alunos. Tem de ser diária, porque escrever só faz sentido se for uma prática regular, do todo sempre. Necessitamos de implementar no aluno uma segunda natureza, a tal ponto que, mesmo quando não está escrevendo, ele esteja elaborando materiais, formulações para a sua escrita, esteja em estado de ensaio. José Donoso, grande escritor chileno, num depoimento em meados dos anos 80, diz: "Faz anos, mais de 30 , que eu escrevo, cada dia, a todo tempo, mesmo quando não estou escrevendo." ${ }^{13} \mathrm{Se}$ guardadas as devidas proporções e o sentido efetivo da produção escrita na escola, é disto que se trata. O fotógrafo vê fotos potenciais em tudo que encontra, está com o click sempre preparado para disparar, ${ }^{14} \mathrm{e}$ acaba fazendo boas fotos porque vive em estado de ensaio. Quem escreve e se envolve com totalidade neste processo de envergadura, deve estar sempre elaborando, sempre em ponto de bala. Outra analogia didática: um jogador de futebol para estar em forma e atuar bem, pratica todo dia, não uma vez ou outra; o violinista, para dar um concerto de primeira, pratica todo dia; qualquer atleta que deseja ir bem em suas competiçōes, pratica todo dia. Tudo isso ocorre porque faz parte de um projeto de vida, como o escrever deve ser. Por isso, por que bastaria escrever uma vez ou outra? A eficácia prática demonstra que isso não gera nenhum resultado adequado. Ou melhor, gera: o apático atraso intelectuai de nossa população estudantil, o que pode ser melhor aferido no baixo nível de desempenho dos jovens que chegam às universidades e sabemos muito bem a quem isso interessa.

Assim posto, se tivermos realmente coragem de ousar, quebrar padrões, vamos enfrentar o trabalho de fazer das aulas de redação efetivamente oficinas de criação, não na ilusão de termos encontrado a panacéia. Todos sabem que a educação será eficaz e humanitária, quando tivermos um sistema social no mínimo justo. Mas, lembrando Paulo Freyre, enquanto o sistema não mudar, podemos ir fazendo alguma coisa. E o sistema também somos nós. Aqui e agora é possível tentar uma outra visão que nos forçará a uma nova prática. Desestruturados e angustiados, talvez possamos encontrar melhores meios de trabalhar nossas ansicdades e, por esta via,

13 Os 40 depoimentos. Leia Livros. São Paulo, n.83, p.24-5, set. 1985.

14 CALKINS, op.cit., p.30. 
pressionar um pouco para a face e a estrutura da educaçāo mudarem. A oficina que estamos propondo tem este objetivo, porque como dizia H.G.Wells em seu maravilhoso romance $A$ máquina do tempo: "Não há inteligência onde nāo há mudanças nem necessidade de mudanças."

\section{RESUMO}

Baseados em nossa experiència como professor de $1^{9}$ e $2^{9}$ graus, propomos que as "aulas de redação" sejam transformadas em "oficinas de texto". Ou seja, que o aluno tenha oportunidade a médio prazo e seguindo vários estágios, de distanciar-se de seu texto para lê-lo e reelaborá-lo criticamente. Fazemos isso num diálogo com o "método" literário seguido pelos escritores. Ainda que escrever literariamente não seja o objetivo da escola, os passos seguidos por um escritor ao confeccionar sua obra servem de ponto de partida para nossa reflexão. É nossa intençāo, com isso, deixar claro que escrever não depende de um talento "superior", mas pode tomar-se uma prática, desde que sejam criadas condiçōes para o seu aprendizado.

\section{REFERÊNCIAS BIBLIOGRÁFICAS}

BAKHTIN, Mikhail. Marxismo e filosofia da linguagem. Sào Paulo: Hucitec, 1979.

CALKINS, Lucy McComick. A ane de ensinar a escrever: o desenvolvimento do discurso escrito. Porto Alegre: Antes Médicas, 1989.

MANDRIK, David; FARACO. Carlos Alberto. Prática de redação para estudantes universitários. Petrópolis: Vozes, 1987.

Os escritores: as historicas entrevistas da Paris Reviw. São Paulo: Companhia das Letras, 1988. v. 1 e $1989, v .2$.

Os 40 depoimentos. Leia Livros. São Paulo, n.83, set.1985.

VYGOTSKY, L.S. A formação social da mente. Sảo Paulo: Martins Fontes Editora, 1984. 